\title{
REMOTE SENSING EFFICIENCY FOR URBAN ANALYSIS OF MECCA AND SURROUNDS
}

\author{
Ayman Imam ${ }^{\text {a,b, } * \text {, Bahaa Alhaddad }}{ }^{\mathrm{c}}$, Josep Roca ${ }^{\mathrm{a}}$ \\ ${ }^{\text {a }}$ CPSV, Centre of Land Policy and Valuations, Polytechnic University of Catalonia (UPC), 08028 Barcelona, Spain. \\ ${ }^{\mathrm{b}}$ Department of Urban and Regional Planning, College of Environmental Design, King AbdulAziz University, Kingdom of Saudi \\ Arabia - aeimam@kau.edu.sa \\ ${ }^{\mathrm{c}}$ Space Dept. Starlab Ltd., Building R103, Harwell Oxford, Didcot OX11 0QX, UK
}

Commission VIII, WG VIII/8

KEY WORDS: Mecca, Land Cover, Change Detection, Remote Sensing, Landsat, Urban Morphology

\begin{abstract}
:
Situated in the southwest of Saudi Arabia, Mecca is considered the spiritual capital of one and a half billion worldwide Muslims. The city is visited by millions of pilgrims every year. It has undergone significant changes in land cover (LC) since the government first embarked on a series of ambitious development projects 20 years ago to accommodate the growing number of pilgrims and citizens. The main objective of our study is to detect, identify, analyze and measure the evolving land cover and urban morphology composition from multi-temporal satellite images. To characterize the morphological change during a period of twenty years, four satellite images, acquired in 1998 by Landsat TM and in 2003, 2008 and 2013 by Landsat ETM+, were classified into five main categories: Urban, Street, Soil and Vegetation. In addition, DEM has been extracted and included as Mountain. Change detection (CD) analysis is applied using post-classification comparison and GIS. As part of the study, morphological index, such as, Entropy is included for better understanding of urban structures behaviour. Mecca and its surroundings show a noticeable increase in urban and vegetation cover. Urban cover (UC) changes were divided into five radial directions: Northeast, Southeast, Southwest, East, and Northwest. These changes are influenced by mountain ranges surrounding the city and the highways. These revelations can play a significant role towards future planning and development activities, which may further promote urban growth.
\end{abstract}

\section{INTRODUCTION}

Rapid urban development and dramatic change of LC have been recently witnessed in some developing countries as a result of rapid economic development (Yeh et al., 2001). LC refers to the physical characteristics of the earth's surface, captured in the distribution of vegetation, water, soil and other physical features of the land, including those created solely by human activities e.g., settlements (Rawat, 2015). LC changes can be detected by identifying differences in its status by observing this at different times (Singh, 1989). Saudi Arabia including Mecca has been changed significantly in its LC during the last 20 years since the government began implementing an intense program of development, financed by huge oil revenues (Mubarak, 2004). The country is recognised as a nation boasting one of the most rapid settlement expansions in the Middle East (Meyer et al., 1994). Special attention was given to Mecca in this development as it is considered the spiritual capital of one and half billion Muslims worldwide and is visited by millions of pilgrims every year. However, Mecca suffers from population growth such as immigration and foreign labour (Ascoura, 2013). As a result of these variables, Mecca urban LC has significantly changed during the last two decades. Considering that the measurement and monitoring of changes in any area are crucial to government officials and planners who need updated information for planning and management purposes (Yeh et al., 2001), the main objective of this paper is to detect, identify, analyse and measure the composition of morphological change from multi-temporal satellite images using morphological indexes, in order to understand the behaviour of urban structures and patterns. Remote sensing (RS) data and techniques, in combination with GIS are fundamental to analyse and characterise LC and its changes (Fichera et al., 2012), because satellite RS provides greater amounts of information on the geographic distribution of LC, along with advantages of cost and time savings for regional size areas (Yuan et al., 2005). Multi-temporal (RS datasets, opportunely processed and elaborated, allow mapping and identifying landscape changes, giving an effective technique to sustainable landscape planning and management (Dewan et al., 2009). The availability of timeseries dataset is essential to understand and monitor the urban expansion process, in order to characterise and locate the evolution trends at a detailed level. During the last three decades, satellite time series, such as Landsat images have been exploited in several studies (Masek et al., 2000). It is widely used for LC monitoring and CD analysis by the use of timeseries analysis for urban sprawl phenomenon (Kamusoko et al., 2013). It is well known that urban morphology becomes an essential key for the urban development to identify and determine the resilience of the whole urban system that will also create urban dynamics. In addition, urban morphology analysis can help to identify the transformation of the urban form development and the evolution of urban form and structure (Cheng, 2011). Entropy is one of the indexes that have been used to describe the structure and behaviour of different systems, such as LC changes (Cabral, 2013), also the advantages of the entropy method are simplicity and easy integration with GIS (Yeh et al., 2001).

\footnotetext{
* Corresponding author
} 


\section{STUDY AREA}

The study area of Mecca is located in the central part of the western region of the Kingdom of Saudi Arabia (Figure 1) at an elevation of 277 metres above sea level, and approximately 80 $\mathrm{km}$ inland from the Red Sea with geographical coordinates lat $\left(21^{\circ} 21^{\prime}\right.$ to $\left.21^{\circ} 27^{\prime}\right) \mathrm{N}$ and long (39 $47^{\circ}$ to $\left.39^{\circ} 59^{\prime}\right)$ E. (Mustapha et al., 2011). According to the Central Department of Statistics and Information (CDSI) census data in 2013, Mecca has a population of 1,867,886 (Alqurashi and Lalit, 2014). As mentioned, Mecca is a unique location for Muslims all over the world, since Muslim should perform pilgrimage (called Hajj, which means visiting Mecca on specific days in the year). Thus, hundreds of thousands of Muslims gather in Mecca yearly will be taken as important variable to be considered in the analysing of urban growth (Al-Ghamdi et al., 2012). The geomorphology has controlled the unique urban pattern of Mecca metropolitan city, which has sprawled in radial direction because of the complex alluvial channels always being separated by the steep mountain ranges, which is also a vital element in the spatial pattern of Mecca (Al Harbi et al., 2012).

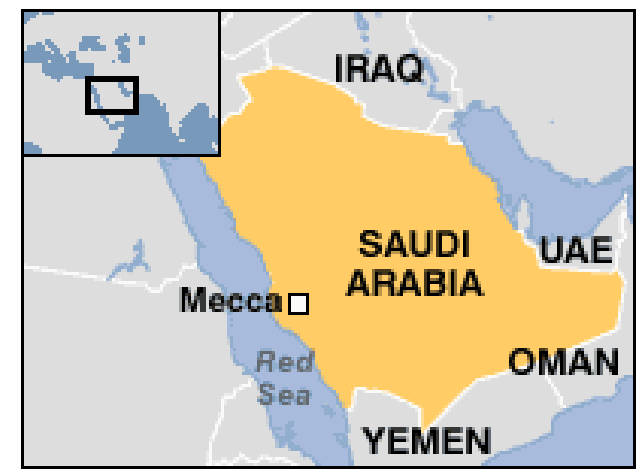

Figure 1. Location Map

\section{MATERIALS AND METHODS}

\subsection{Satellite data}

A multi-temporal set of RS data of the area of interest is used to study and classify the land cover. The set includes Landsat images TM 1998, ETM+2003, 2008 and 2013), collected on 25 August 1998, 15 August 2003, 28 August 2008 and 26 August 2013 (table 1). All images have been calibrated. The sub-setting of satellite images performed for extracting an area covering approximately 1200 square as our study area from all images by taking the geo-referenced out line boundary of Mecca and surrounds map as AOI (Area of Interest).

\begin{tabular}{|c|c|c|c|}
\hline $\begin{array}{c}\text { Respective } \\
\text { year }\end{array}$ & $\begin{array}{c}\text { Date Acquired } \\
\text { (Day/Month/year) }\end{array}$ & Sensor & Resolution \\
\hline 1998 & $25 / 08 / 1998$ & $\begin{array}{c}\text { Landsat } 5 \\
\text { TM }\end{array}$ & $30 \mathrm{~m}$ \\
\hline 2003 & $15 / 08 / 2003$ & $\begin{array}{c}\text { Landsat 7 } \\
\text { ETM+ }\end{array}$ & $30 \mathrm{~m}$ \\
\hline 2008 & $28 / 08 / 2008$ & $\begin{array}{c}\text { Landsat } 7 \\
\text { ETM+ }\end{array}$ & $30 \mathrm{~m}$ \\
\hline 2013 & $26 / 08 / 2013$ & $\begin{array}{c}\text { Landsat } 7 \\
\text { ETM+ }\end{array}$ & $30 \mathrm{~m}$ \\
\hline
\end{tabular}

Table 1. Details of Landsat satellite images

\subsection{Dataset pre-preparation}

For the geospatial and spectral analysis, ENVI 5.1 in combination with GIS have been used to process and analyse the data to achieve the main objectives. A number of preprocessing steps were undertaken, such as images' gaps filled and resolution enhancement. The gaps filling process was applied, because the sensor of Landsat 7 Enhanced Thematic Mapper (ETM) had a failure of the Scan Line Corrector (SLC) on May 2003, and all images after that time had wedge-shaped gaps on both sides of each scene, resulting in loss of data of approximately $22 \%$, which has seriously limited the scientific applications of ETM+ data (Chen et al., 2011). A number of methods have been developed since that failure to fill the unscanned gaps in ETM+ images (Maxwell, 2004). a technique developed by Scaramuzza et al. (2004) used to fill gaps in one scene with data from another Landsat scene. This technique applied to the images 2003, 2008 and 2013. Furthermore, the pan-sharping method was used in order to enhance the images resolution of Landsat 7 Thematic Mapper Plus (ETM+). The method merges the multispectral bands with the 15-metre panchromatic band, without losing the RGB information from the original multispectral three-band 30-metre composite. The objective of the sharpening was to improve the spatial resolution of the multispectral imagery, while preserving the spectral information in homogeneous areas (King and Jianwen, 2001).

\subsection{Image classification}

Image classification refers to grouping image pixels into categories or classes to produce a thematic representation (Canada Centre for Remote Sensing, 2010). In recent years, many advanced methods have been applied, each of which has both strengths and limitations (Mustapha et al., 2011). In this study, several approaches are applied to boost the classification accuracy, such as supervised technique to categorise our classes, normalised difference vegetation index (NDVI) to extract the vegetation cover and finally the method of building a multi-index image applied to enhance the classification results. To calculate the LC classification, minimum distance, maximum likelihood and neural network are applied to extract the most accurate class in each scene. Five classes were established as Urban, Street, Soil, Vegetation and Mountain class. Descriptions of these LC classes are presented in Table 2.

\begin{tabular}{|l|l|}
\hline LC Classes & Description \\
\hline Urban & $\begin{array}{l}\text { Residential, commercial services, industrial, mixed } \\
\text { urban or built-up land }\end{array}$ \\
\hline Street & Including all roads network \\
\hline Soil & Bare soil, sandy soil, desert, open land \\
\hline Vegetation & Trees, agriculture area, vegetated area \\
\hline Mountain & Hill, large rock, rugged terrain \\
\hline
\end{tabular}

Table 2. LC classification scheme

The use of NDVI allows transforming multispectral data into a single image band representing vegetation distribution, as the amount of green vegetation present in the pixel. Therefore, NDVI values range from -1 to +1 , where negative values correspond to an absence of vegetation (Pettorelli et al., 2005) (Figure 2). 


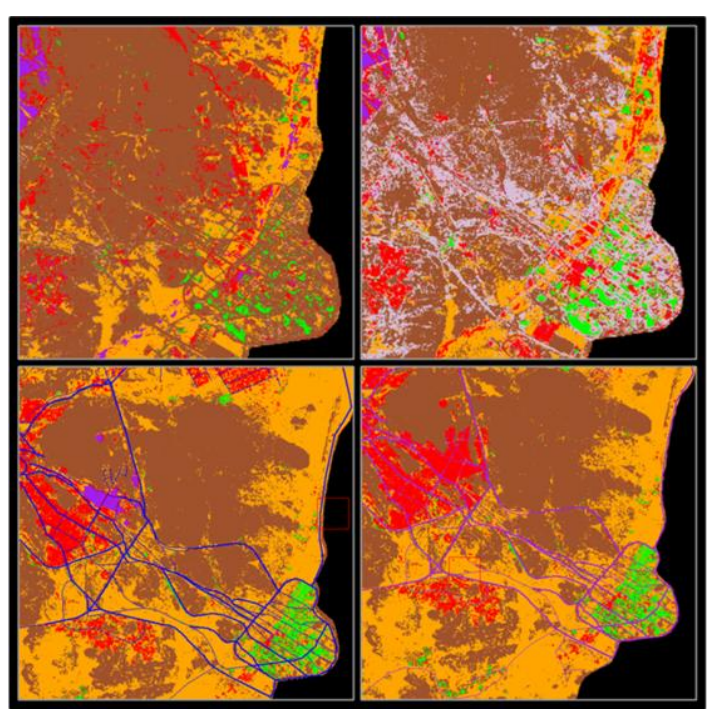

Figure 2. LC classification testing step

\subsection{Classification improvement using multi index images}

The objective of this step is to enhance the spectral information through the generation of additional layers (in addition to the information provided by Landsat) in order to minimise the classification errors, such as the effects of the environment and then the "noise" due to the overlapping between different classes. The method is about generating a multi-indices image, based on 28 indices, such as Linear Spectral Unmixing (LSU), Tasseled cap vegetation index, the Enhanced Vegetation Index (EVI), Normalised Difference Soil Index (NDSI) and the Soil Adjusted Vegetation Index (SAVI)...etc. (Figure 3).

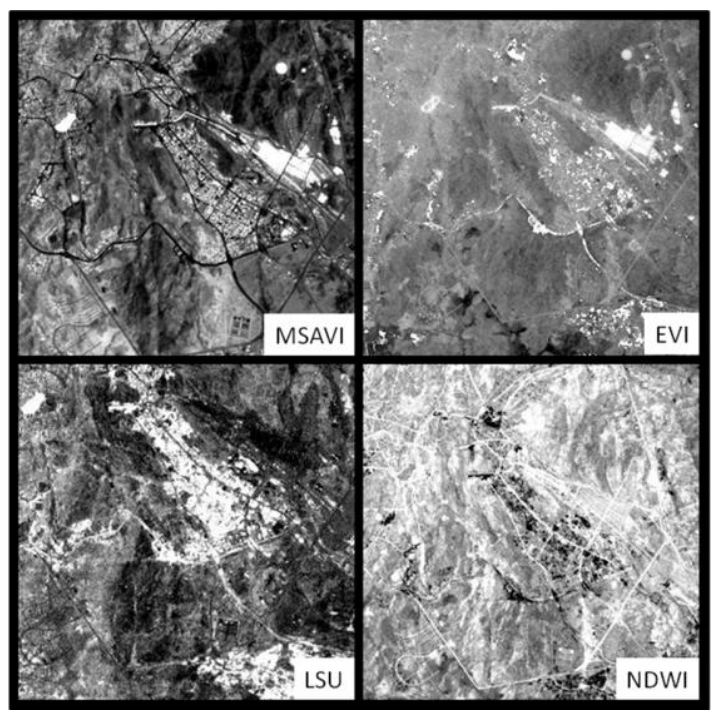

Figure 3. Images represent some applied indices

Thereafter, once the multi-index image is completed, the selection of pixels through ROI that represents the peak of each band is applied in order to test the supervised classification technique again. This step is repeated to all images to get the best possible classification result with a view to compare this with previous results to extract the best classes possible of each category. Finally, four different LC maps for all periods of study were produced. (Figure 4).

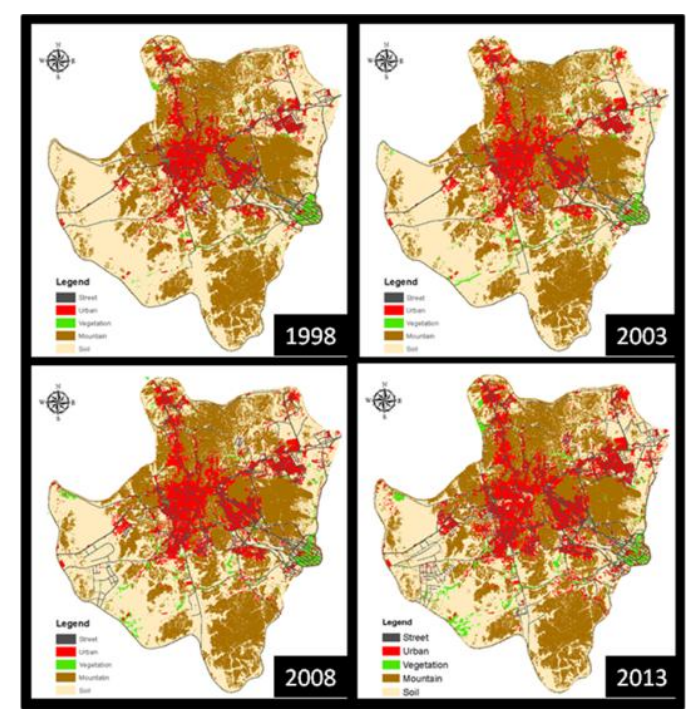

Figure 2. LC maps for all periods of study

\subsection{Accuracy Assessment}

The term of accuracy used typically expresses the degree of 'correctness' of a map or classification (Foody, 2002), and the confusion matrix method through the ground truth data was applied to the classified images in order to calculate and tabulate the overall accuracy and Kappa Coefficient, and to evaluate the user's and the producer's accuracy. For each LC class, a validation dataset (about 500 pixels per class) was designated using stratified random sampling. The results obtained show an overall accuracy of $84.64 \%, 84.8 \%, 83.56 \%$ and $83.72 \%$ for $1998,2003,2008$ and 2013 respectively.

\section{RESULTS AND DISCUSSION}

\subsection{Land Cover Status}

The post-classification comparison was applied to determine the difference between independently classified images by comparing thematic classifications produced for each date. This analysis is helpful to identify various changes occurring in different classes of land use, such as increase in urban area or decrease in vegetation cover and so on (Hegazy et al., 2015).

The results obtained through the analysis of multi-temporal satellite imageries are diagrammatically illustrated in Figure 4, and the individual class area and change statistics for the four years for Mecca are registered in tables 3.

\begin{tabular}{cccccccc}
\hline \multirow{2}{*}{$\begin{array}{c}\text { Land } \\
\text { Cover } \\
\text { Category }\end{array}$} & $\mathbf{1 9 9 8}$ & $\mathbf{2 0 0 3}$ & $\mathbf{2 0 0 8}$ & $\mathbf{2 0 1 3}$ & \multicolumn{2}{c}{$\mathbf{1 9 9 8} \mathbf{- 2 0 1 3}$} \\
\cline { 2 - 7 } & Area & Area & Area & Area & \multicolumn{2}{c}{ Change } \\
\cline { 2 - 7 } & $\left(\mathbf{K m}^{2}\right)$ & $\left(\mathbf{K m}^{2}\right)$ & $\left(\mathbf{K m}^{2}\right)$ & $\left(\mathbf{K m}^{2}\right)$ & $\left(\mathbf{K m}^{2}\right)$ & \% \\
\hline Urban & 77.29 & 90.61 & 106.57 & 121.16 & 43.86 & 56.76 \\
Vegetation & 8.13 & 12.75 & 13.22 & 18.45 & 10.32 & 126.94 \\
Street & 26.43 & 27.21 & 33.06 & 34.40 & 7.97 & 30.16 \\
Soil & 598.27 & 579.56 & 565.25 & 567.62 & -30.65 & -5.12 \\
Mountain & 496.70 & 496.68 & 488.73 & 465.20 & -31.51 & -6.34 \\
Total & 1206.83 & 1206.83 & 1206.83 & 1206.83 & & \\
\hline
\end{tabular}

Table 3 . The changes for all classes during the period of study 
The percentages of land cover change from the total land cover of 1998, 2003, 2008 and 2013 are also shown in the table. It is clear from the table that there has been a considerable change in land cover in Mecca during the 20-year study period. Urban area increased by approximately $43.86 \mathrm{~km}^{2}$ (56.76\%). There was also an increase in both vegetation and street cover by approximately $10.32 \mathrm{~km}^{2}(126.94 \%)$ and $7.97 \mathrm{~km}^{2}(30.16 \%)$ respectively. Mountain is the dominant land cover class in Mecca, and the soil class forms another major class of land cover. Both Mountain and Soil cover show a decrease of $31.51 \mathrm{~km}^{2}(-6.34 \%)$ and $-30.65 \%(-6.34 \%)$ respectively, as a result of the increase in other classes.

\subsection{Urban Cover Analysis}

For better understanding of urban structures and behaviour, the urban cover obtained from the classification for the four years were divided into five main parts namely; Northeast (NEP), Southeast (SEP), Southwest (SWP), West (WP), and Northwest (NWP) in order to calculate the percentage of change for each part, and to discover which part had the highest percentage of change. Those parts were divided according to the direction of urban change influenced by the surrounding mountains and the highways located in these parts that connect Mecca with five important cities of Jeddah, Al-madinah, Riyadh, Taif and Jizan (Figure 5).

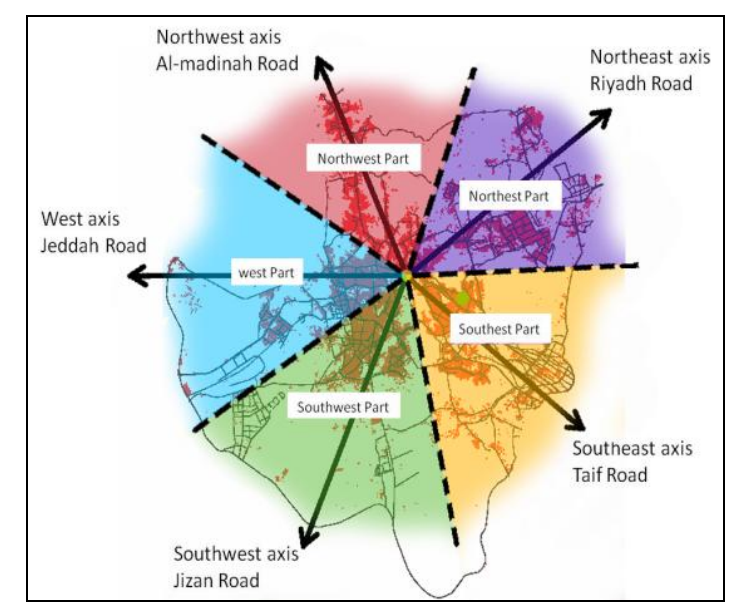

Figure 5. Growth direction and parts

The results show that the high percentage of change between 1998 and 2013 were in NEP and SEP by an increase of 14.27 $\mathrm{km}^{2}(89.1 \%)$ and $11.20 \mathrm{~km}^{2}(71.18 \%)$ respectively (table 4$)$, which represent approximately $58.2 \%$ of the total urban cover change of Mecca, which could be a result of the impact of the sacred sites of pilgrimage located there; thus, urban development is affected by pilgrims' activities (Ascoura, 2013).

\begin{tabular}{|c|c|c|c|c|c|c|}
\hline \multirow{3}{*}{$\begin{array}{l}\text { The main } \\
\text { parts of } \\
\text { urban cover } \\
\text { growth }\end{array}$} & \multirow{3}{*}{\begin{tabular}{l|}
1998 \\
Area \\
$\mathrm{Km}^{2}$
\end{tabular}} & \multirow{3}{*}{\begin{tabular}{r|}
2003 \\
Area \\
$\mathbf{K m}^{2}$
\end{tabular}} & \multirow{3}{*}{$\begin{array}{c}2008 \\
\text { Area } \\
\mathrm{Km}^{2}\end{array}$} & \multirow{3}{*}{$\begin{array}{c}2013 \\
\text { Area } \\
\mathrm{Km}^{2}\end{array}$} & \multirow{2}{*}{\multicolumn{2}{|c|}{$\begin{array}{c}1998 \text { - } 2013 \\
\text { Total change }\end{array}$}} \\
\hline & & & & & & \\
\hline & & & & & $\mathbf{K m}^{2}$ & $\%$ \\
\hline NWP & 16.36 & 18.28 & 21.29 & 22.87 & 6.51 & 39.78 \\
\hline NEP & 16.02 & 19.22 & 23.90 & 30.30 & 14.27 & 89.10 \\
\hline SEP & 14.72 & 19.53 & 22.63 & 25.92 & 11.20 & 76.04 \\
\hline SWP & 15.15 & 17.35 & 20.16 & 23.48 & 8.33 & 55.02 \\
\hline WP & 15.04 & 16.24 & 18.60 & 18.59 & 3.55 & 23.58 \\
\hline Total & 77.30 & 90.62 & 106.58 & 121.16 & 43.86 & 56.75 \\
\hline
\end{tabular}

Table 4. Urban cover changes of each part
On the other hand, the lowest percentage of change was in WP by an increase of only $3.55 \mathrm{~km}^{2}(23.58 \%)$ as the city centre is located there, which does not change considerably, and is consistent with other city centres worldwide. In general, the distribution of urban areas in Mecca has been influenced by the topography, which controls the trend of urbanisation (Alqurashi et al., 2014) (Figure 6).

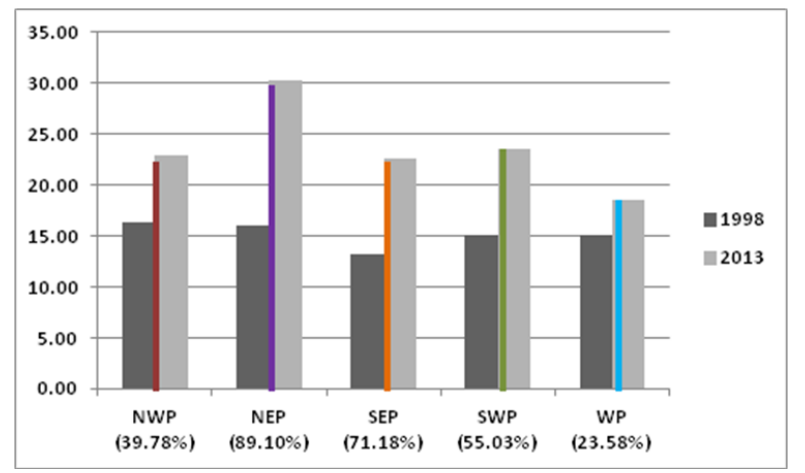

Figure 6. Chart comparing the percentage of change among different parts

Furthermore, the entropy was applied by the subdivision of the windows of 1887.18 sq. km into a grid composed of cells of .01 sq. $\mathrm{km}$, which enables the calculation of the entropy value (high/low) for each cell. The highest cell value is 1 and the lowest is 0 , cell values close to zero indicate that there is more chance to change, and cell values close to one indicate that change is less likely. Urban development often requires high values (Cabral, 2013), so in this study the parts with higher entropy values indicate greater opportunities of change and growth and vice versa (Figure 7).

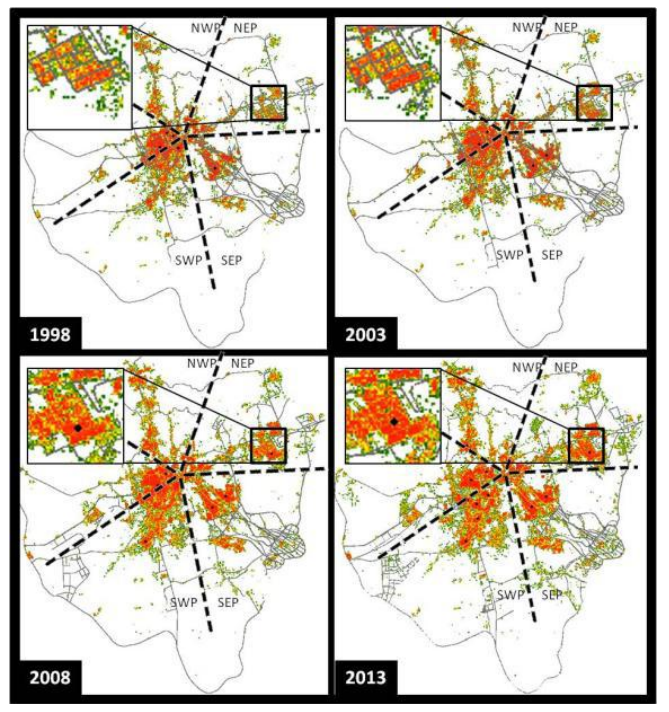

Figure 7. The maps of the Entropy index calculation

Result of the entropy index shows that the total number of calculated cells has increased by approximately $54.33 \%$ from 16968 cells in 1998 to 26187 cells in 2013, and the number of high values cells also increased by $51.97 \%$ from 10021 cells in 1998 to 15229 . The change statistics for the four years and for each part are registered in tables 5. This table also illustrates that the NEP and SEP are the parts with the highest number of 
high values in 2013 and the NEP has the highest values during all years of study, while the WP has the lowest number of high values, which indicate that the NEP and SEP have greater opportunities of growth and expansion than others, due to the increase in public services, buildings and road networks connecting different pilgrimage site facilities located there. However the WP has the lowest number of high values, and has the highest percentage of change during the 20 years of study, as a result of demolition works and development in the central part of Mecca, where the holy mosque is located.

\begin{tabular}{|c|c|c|c|c|c|}
\hline \multirow{7}{*}{$\begin{array}{r}4500 \\
4000 \\
3500 \\
3000 \\
2500 \\
2000 \\
1500 \\
1000 \\
500 \\
0\end{array}$} & & & & & \\
\hline & & & & & \\
\hline & & & & & \\
\hline & & & & & \\
\hline & & & & & \\
\hline & & & & & \\
\hline & NEP & NWP & SEP & SWP & WP \\
\hline High Ent. 1998 & 2499 & 2075 & 2006 & 2467 & 1115 \\
\hline High Ent. 2003 & 2670 & 2184 & 2261 & 2565 & 1171 \\
\hline High Ent. 2008 & 3170 & 2254 & 2700 & 2741 & 1502 \\
\hline High Ent. 2013 & 4118 & 2524 & 3561 & 2960 & 2280 \\
\hline
\end{tabular}

Table 5. The change of high entropy values for all parts

\section{CONCLUSION}

The study aimed to use satellite remotely sensed images (i.e. Landsat) to detect changes in Mecca LC between 1998 and 2013 in order to understand the pattern of change. The study has successfully detected the LC changes and concludes that the area of the urban and vegetation cover has increased, whereas the area of mountain and soil cover has decreased. The pattern of the urban cover change analysis demonstrates that the urban pattern of Mecca is influenced by the surrounding mountains and the highways, which distribute urban growth into five parts. It is also noted that the southeast and northeast parts of the city have increased more than other parts, as these have greater opportunities for faster growth because of the impact of pilgrimage sites and facilities located there. This paper shows that information from RS can play a useful role in understanding the nature of change in the LC, where they occur, and project possible or likely future changes. Such information is essential when planning for development and preserving our natural resources and environment, and is needed by urban planners and citizens. Our continuing work includes applying other urban morphology indexes, in order to understand the pattern of Mecca's urban cover changes in greater depth.

\section{ACKNOWLEDGMENT}

The authors would like to thank Starlab Ltd and the Centre of Land Policy and Valuations (CPSV) for their support and supervision of this work.

\section{REFERENCES}

Al Harbi, K., El Bastawesy, M., Habeebullah, T. \& Mandour, M., (2012), Assessment of Landslides of the Hill Slopes in Makkah Using Remote Sensing and GIS Techniques, Journal of American Science, 8(3)
Al-Ghamdi, K., Mirza, M., Elzahrany, R. \& Dawod, G., (2012), GIS evaluation of urban growth and flood hazards: a case study of Makkah City, Saudi Arabia, The International FIG Working Week, pp. 6-10

Alqurashi, A.F. \& Kumar, L., (2014), Land Use and Land Cover Change Detection in the Saudi Arabian Desert Cities of Makkah and Al-Taif Using Satellite Data, Advances in Remote Sensing, 3(03), pp. 106-109

Ascoura, I.E., (2013), Impact of Pilgrimage (Hajj) on the Urban Growth of the Mecca, Journal of Educational and Social Research, 3(2), pp. 255-263

Cabral, P., Augusto, G., Tewolde, M. \& Araya, Y., (2013), Entropy in urban systems, Entropy, 15(12), pp. 5223-5236

Canada Centre for Remote Sensing, Natural Resources Canada, Ottawa, Ontario, K1A 0Y7, available from http://www.ccrs.nrcan.gc.ca/glossary/index_e.php , accessed on 15-11-2010

Chen, J., Zhu, X., Vogelmann, J.E., Gao, F. \& Jin, S., (2011), A simple and effective method for filling gaps in Landsat ETM+ SLC-off images, Remote Sensing of Environment, 115(4), pp. 1053-1064

Colaninnoa, N., Rocaa, J., Burnsa, M. \& Alhaddada, B., (2012), Defining Densities for Urban Residential Texture, Through Land Use Classification, from Landsat TM Imagery: Case Study of Spanish Mediterranean Coast, ISPRS-International Archives of the Photogrammetry, Remote Sensing and Spatial Information Sciences, 1, pp. 179-184

Fichera, C.R., Modica, G. \& Pollino, M., (2012), Land Cover classification and change-detection analysis using multitemporal remote sensed imagery and landscape metrics, European Journal of Remote Sensing, 45(1), pp. 1-18

Foody, G.M., (2002), Status of land cover classification accuracy assessment, Remote sensing of environment, 80(1), pp. $185-201$

Hegazy, I.R. \& Kaloop, M.R., (2015), Monitoring urban growth and land use change detection with GIS and remote sensing techniques in Daqahlia governorate Egypt, International Journal of Sustainable Built Environment

King, R.L. \& Wang, J., (2001), A wavelet based algorithm for pan sharpening Landsat 7 imagery, In Geoscience and Remote Sensing Symposium, 2001, IGARSS'01, IEEE 2001 International (Vol. 2, pp. 849-851), IEEE

Maxwell, S., (2004), Filling Landsat ETM+ SLC-off gaps using a segmentation model approach, Photogrammetric Engineering and Remote Sensing, 70(10), pp. 1109-1112

Meyer, W.B. \& Turner, B.L. II, (1994), Changes in land use and land cover: a global perspective (Vol. 4), Cambridge University Press

Mubarak, F.A., (2004), Urban growth boundary policy and residential suburbanization: Riyadh, Saudi Arabia, Habitat International, 28(4), pp. 567-591 
Mustapha, M.R., San, L.H., Jafri, M.Z.M. \& Syahreza, S., (2011), Land Cover Classification in Makkah Area using Frequency-based Contextual Classifier, In International Conference on Environment Science and Engineering IPCBEE (Vol. 8)

Pettorelli, N., Vik, J.O., Mysterud, A., Gaillard, J.M., Tucker, C. J. \& Stenseth, N.C., (2005), Using the satellite-derived NDVI to assess ecological responses to environmental change, Trends in ecology \& evolution, 20(9), pp. 503-510

Pirotti, F., Parraga, M.A., Stuaro, E., Dubbini, M., Masiero, A. \& Ramanzin, M., (2014), NDVI from Landsat 8 Vegetation Indices to Study Movement Dynamics of Capra Ibex in Mountain Areas, ISPRS-International Archives of the Photogrammetry, Remote Sensing and Spatial Information Sciences, 1, pp. 147-153

Rawat, J.S. \& Kumar, M., (2015), Monitoring land use/cover change using remote sensing and GIS techniques: A case study of Hawalbagh block, district Almora, Uttarakhand, India, The Egyptian Journal of Remote Sensing and Space Science

Scaramuzza, P., Micijevic, E. \& Chander, G., (2004), SLC gapfilled products phase one methodology, Landsat Technical Notes

Yeh, A.G.O. \& Xia, L., (2001), Measurement and monitoring of urban sprawl in a rapidly growing region using entropy, Photogrammetric engineering and remote sensing, 67(1), pp. 83-90

Yuan, F., Sawaya, K.E., Loeffelholz, B.C. \& Bauer, M.E., (2005), Land cover classification and change analysis of the Twin Cities (Minnesota) Metropolitan Area by multi-temporal Landsat remote sensing, Remote sensing of Environment, 98(2), pp. $317-328$ 